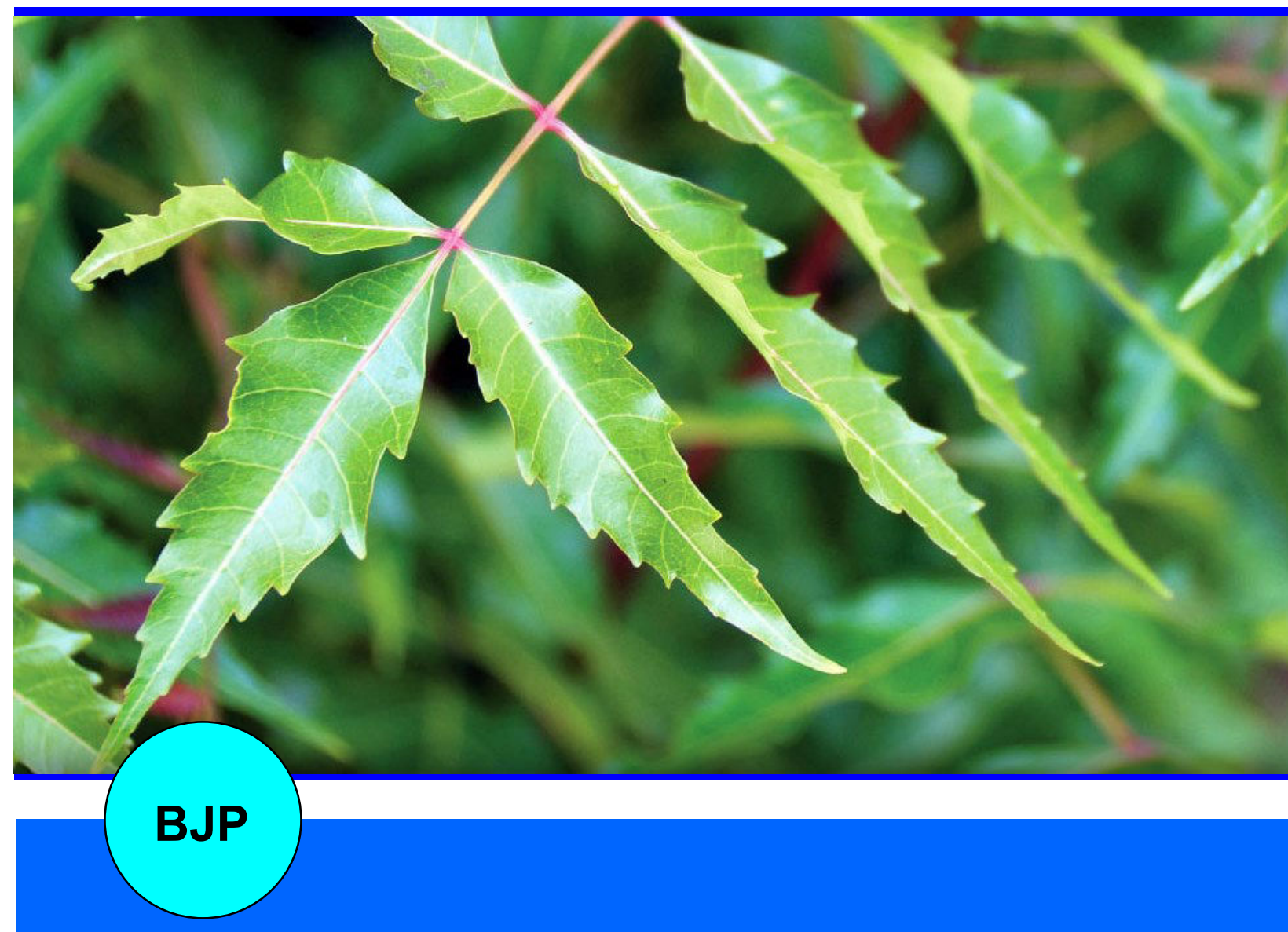

Bangladesh Journal of Pharmacology

Research Article

A comparative study of the antiinflammatory effect of aqueous extract of neem leaf and dexamethasone 
Abstracted/indexed in Academic Search Complete, Asia Journals Online, Bangladesh Journals Online, Biological Abstracts, BIOSIS Previews, CAB Abstracts, Current Abstracts, Directory of Open Access Journals, EMBASE/Excerpta Medica, Google Scholar, HINARI (WHO), International Pharmaceutical Abstracts, Open J-gate, Science Citation Index Expanded, SCOPUS and Social Sciences Citation Index;

ISSN: $1991-0088$

\title{
A comparative study of the anti-inflammatory effect of aqueous extract of neem leaf and dexamethasone
}

\author{
Abu Syed Md. Mosaddek and Md. Mamun Ur Rashid \\ Department of Pharmacology, Rajshahi Medical College, Rajshahi, Bangladesh.
}

Article Info
$\begin{aligned} & \text { Received: } \\ & \text { Accepted: }\end{aligned}$
$\begin{aligned} & \text { Available Online: } \\ & \text { DOI: } 10.3329 / \text { bjp.v3i1.836 } 2008\end{aligned}$
$\begin{aligned} & \text { Cite this article: } \\ & \text { Mosaddek ASM, Rashid } 2008\end{aligned}$
$\begin{aligned} & \text { comparative study of the anti-infla- } \\ & \text { mmatory effect of aqueous extract of } \\ & \text { neem leaf and dexamethasone. Bang- } \\ & \text { ladesh J Pharmacol. 2008; 3: 44-47. }\end{aligned}$

\begin{abstract}
The anti-inflammatory effect of aqueous extract of neem leaf $(400 \mathrm{mg} / \mathrm{kg}$ body weight) was compared with that of dexamethasone $(0.75 \mathrm{mg}$, intraperitoneally) by administering one hour before the formalin injection and once daily for 7 days in rats. The percentage of inhibition of paw edema in case of neem after 3, 6 hours, on day 3, 7 after formalin injection were 28, 40, 45, 58\% respectively and that in case of dexamethasone after 3,6 hours, on day 3, 7 after formalin injection were $43,58,61,65 \%$ respectively. The reduction was statistically significant in each case $(\mathrm{p}<0.001)$. The present study suggests that anti-inflammatory effect of neem extract is less than that produced by dexamethasone.
\end{abstract}

\section{Introduction}

Inflammation is fundamentally a protective response, ultimate goal of which is to get rid the noxious but sometimes it may be potentially harmful and needs pharmacological treatment to control its symptoms (Kumar et al., 2004).

Many anti-inflammatory drugs (both NSAIDs and corticosteroids) have been developed but their safety profile studies have shown that none of them is clearly safe (Rang et al., 2003). They show wide ranges of adverse effects. Due to adverse reactions of synthetic and chemical medicines being observed round the globe, herbal medicines have made a come back to improve our basic health needs. Many plants and herbs such as ginger, turmaric, olive oil, have been shown to exhibit potent anti-inflammatory effect. Neem is reported in ayurvedic, tibbi and homoepathetic system of medicine to be useful in rheumatic disorders (Biswas et al., 2002).
Biswas et al. (2002) have also shown that different types of extracts from various parts of neem tree (bark, seed, leaf) have anti-inflammatory, anti-pyretic, analgesic, immunostimulant, hypoglycemic, antiulcer, anti-fertility anti-malarial, antibacterial, antifungal, anti-viral, anti-carcinogenic, anti-oxidant, hepatoprotective effects.

More than 135 compounds have been isolated from different parts of neem. Some of them such as nimbin, nimbinin, nimbidinin, nimbolide and nimbidic, are biologically active (Chatterjee and Pakrashi, 1994).

The chloroform extract of stem bark is effective against carrageenin-induced paw edema in rat and mouse ear inflammation (Tidjani et al., 1989). Neem leaf extract exerted significant anti-inflammatory effect in cotton pallet granuloma in rats (Chattopadhyay, 1998).

The present study was carried out to compare the antiinflammatory effect of neem with dexamethasone. 
Table I

Effects of neem extract and dexamethasone on circumferential length of the hind paw edema

\begin{tabular}{|ccc|c|c|c|c|}
\hline \multirow{2}{*}{ Group } & Treatment & \multicolumn{5}{c|}{ Circumferential length $(\mathrm{mm})$ of hind paw edema } \\
\cline { 3 - 7 } & & Before & Increase after & Increase after & Increase on & Increase on \\
& & treatment & 3 hours & 6 hours & $3^{\text {rd }}$ day & 7 th day \\
I & Control $(0.5 \mathrm{~mL}$ distilled water) & $16.0 \pm 0.4$ & $13.5 \pm 0.3$ & $14.5 \pm 0.4$ & $12.2 \pm 0.5$ & $9.2 \pm 0.4$ \\
II & Neem $(400 \mathrm{mg} / \mathrm{kg})$ & $15.5 \pm 0.4$ & $9.7 \pm 0.4$ & $8.7 \pm 0.4$ & $6.7 \pm 0.3$ & $4.8 \pm 0.3$ \\
III & Dexamethasone $(0.75 \mathrm{mg})$ & $15.5 \pm 0.4$ & $7.7 \pm 0.3$ & $6 \pm 0.5$ & $4.7 \pm 0.6$ & $3.2 \pm 0.6$ \\
\hline
\end{tabular}

Values are expressed in Mean \pm SEM

\section{Materials and Methods}

The experiments were carried out on 30 Albino rats of either sexes aged two and half months, weighting 150$250 \mathrm{~g}$, collected from the animal house of International Center for Diarrheal Diseases Research of Bangladesh, Dhaka.

The leaves of neem were collected, washed with clean water and dried and powdered. They were grinned and mixed in 4 liters of distilled water and allowed to sock overnight. The suspension was centrifuged at speed of 3,000 rpm and filtered through a Whitman No. 1 filter paper. The supernatant fluid was allowed to evaporate in glass petri dishes. When completely dry, the powder was collected by scraping and was stored. Stock solution was prepared by dissolving $500 \mathrm{mg}$ of extract in $5 \mathrm{ml}$ of distilled water. The dose of neem leaf extract is $1.0 \mathrm{~mL}$ of solution, used in the experiment representing $400 \mathrm{mg} / \mathrm{kg}$ body weight. Active ingredient of dexamethasone, used in this experiment was collected from the General Pharmaceutical Company, Bangladesh. The stock solution of dexamethasone was prepared by dissolving $20 \mathrm{mg}$ of dexamethasone in 1 $\mathrm{mL}$ of alcohol.

The rats were divided into three groups. One group received $0.5 \mathrm{~mL}$ distilled water intraperitoneally one hour before the formalin injection and once daily for 7 days. The animals of Group II were given aqueous extract of neem at a dose of $400 \mathrm{mg} / \mathrm{kg}$ body weight intraperitoneally one hour before the formalin injection and once daily for 7 days. Another group received dexamethasone at a dose of $0.75 \mathrm{mg}$ intraperitoneally one hour before the formalin injection and once daily for 7 days.

Paw edema was produced in the right hind paw of rats by injecting $0.1 \mathrm{~mL}$ of $2 \%$ formalin in $0.9 \% \mathrm{NaCl}$ subcutaneously in the planter surface near the central region of planter aponeurosis (Damas and Liegeois, 1999).
The percentages of inhibition of increased circumferential length of hind paw edema of rats in both the control and drug- treated groups were compared by using formula: $\{(C-T), C\}^{\prime} 100$ where $T$ and $C$ stands for test and control respectively (Ray et al., 1980).

Progress of local inflammatory exudative lesion was assessed by measuring the circumferential length one hour before formalin injection and 3, 6 hours, once daily for 7 consecutive days after injection of formalin. The mean increase in the circumferential length of the hind paw edema were taken for calculation.

In the present study, taking measurement of mean increase in the circumferential length of rat's hind paw edema respectively assessed inflammation.

All values expressed as mean \pm SEM, where SEM represents the standard error of mean. Students' unpaired ' $t$ ' test was performed to evaluate the statistical differences. The $p$ value of 0.05 or less was regarded as significant.

\section{Results}

The circumferential length $(\mathrm{mm})$ of hind paw before injection of formalin in control, neem extract and dexamethasone groups were $16.0 \pm 0.4,15.5 \pm 0.4$ and $15.5 \pm$ $0.4 \mathrm{~mm}$ respectively (Table I). After injection the circumferential length was increased. These increased circumferential lengths were inhibited by neem extract and dexamethasone. The percentage of inhibition of paw edema in case of neem after 3,6 hours, on day 3,7 after formalin injection were $28,40,45,58 \%$ respectively and that in case of dexamethasone after 3, 6 hours, on day 3, 7 after formalin injection were 43, 58, 61, 65\% respectively. The reduction was statistically significant in each case $(\mathrm{p}<0.001)$. 


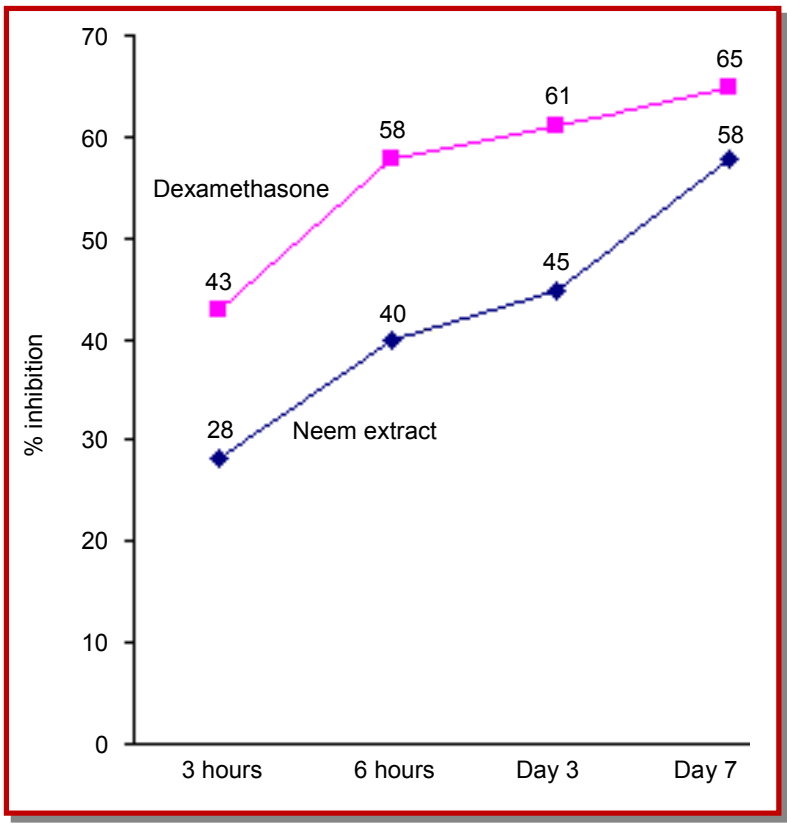

Figure 1: Inhibition of hind paw edema by neem extract and dexamethasone after different times

\section{Discussion}

The present study has been undertaken to demonstrate the anti-inflammatory effect of neem leaf extract and to compare the anti-inflammatory effect of neem with that of dexamethasone. Dexamethasone is very potent well known anti-inflammatory steroid. Another agent is widely used well-known herbal agent neem. In this study measurement of effects of neem extract and dexamethasone on circumferential length of the hind paw edema was done after 3, 6 hours, on day 3 and 7 of inducing inflammation by formalin injection. A single subcutaneous injection of $0.1 \mathrm{~mL}$ of $2 \%$ formalin in rats produced inflammation significantly $(\mathrm{p}<0.001)$. In experimental groups, reduction of inflammation was highly significant but anti-inflammatory effect of dexamethasone is more pronounced than that of neem leaf extract.

Similar observations were made by number of researchers. Water soluble part of alcoholic extract of neem leaves at a dose of $200 \mathrm{mg} / \mathrm{kg}$ orally exerted significant anti-inflammatory activity in cotton pellet granuloma assay and also inhibited the biochemical mode of action on inflammation significantly. This anti-inflammatory activity of neem leaf extract might be due to stabilization of lysosomal membranes and anti-proliferative effect (Chattopadhyay, 1998).
Chattopadhyay et al. (1993) also done experiment with Azadirachta indica leaf extract and reported that its antiinflammatory effect is by inhibiting action of 5-HT and $\mathrm{PGE}_{1}$ on inflammatory edema induced by chemical mediators such as 5-HT, histamine, bradykinin and PGE1.

Aqueous leaf extract of neem produced significant antinociceptive activity at a dose of $500 \mathrm{mg} / \mathrm{kg}$ body weight in rats (Khosla et al., 2000).

Okpanyi and Ezeukwa (1981) reported the profound anti-inflammatory effect of neem extract. It is at a dose of $400 \mathrm{mg} / \mathrm{kg}$ body weight equipotent to $50 \mathrm{mg} / \mathrm{kg}$ acetylsalicylic acid and $4 \mathrm{mg} / \mathrm{kg}$ indomithacin.

Nimbidin, a crude extract of neem extract at a dose of $80 \mathrm{mg} / \mathrm{kg}$ showed significant anti-inflammatory effect that is almost similar to that of predinisolone at a dose of $10 \mathrm{mg} / \mathrm{kg}$ (Pallai and Shanthakumari, 1981).

From the results in this study it can be concluded that neem leaf extract exhibits significant anti-inflammatory effect but it is less efficacious than that of dexamethasone. Further study may be done to find out the exact anti-inflammatory mechanism of action of neem.

\section{References}

Biswas K, Chattopathyay I, Banerjee RK, Bandyopathyay U. Biological activities and medicinal properties of neem (Azadirachta indica). Curr Sci. 2002; 82: 1336-45.

Chatterjee A, Pakrashi S. (ed). The treatise on Indian medical plants. 3rd ed. 1994, p 76

Chattopadhyay RR. Study of possible biochemical mode of anti-inflammatory action of Azadirachta indica in rats. Indian J Experimental Biol. 1998; 36: 418-20.

Chattopadhyay RR, Chattopadhyay RN, Maitra SK. Study of possible mechanism of anti-inflammatory activity of Azadirachta indica leaf extract. Indian J Pharmacol. 1993; 25: 99-100.

Khosla P, Sangeeta B, Singh J, Srivastava RK. Study of antinociceptive activity of Azadirachta indica (neem) in rats. Indian J Pharmacol. 2000; 32: 372-74.

Damas J, Liegeosis JF. The inflammatory reaction induced by formalin in rats paw. Naunyn Schmiedebegs Arch Pharmacol. 1999; 359: 220-27. http://dx.doi.org/10.1007/ PL00005345

Kumar V, Abbas AK, Fausto N. Pathologic basis of disease. $7^{\text {th }}$ ed. Elsevier Saunder, 2004.

Okpanyi SN, Ezeukwu GC. Studies of anti-inflammatory and anti-pyretic activities of Azadirachta indica on inflammation 
in Sprague-Dawley male rats. Planta Med. 1981; 41: 34-39.

Pallai NR, Shanthakumari G. Study of anti-arthritic and antiinflammatory actions of nimbidin on inflammation in albino rats. Planta Med. 1981; 43: 59-63.

Rang HP, Dale MM, Ritter JM, Moore PK. (eds). Pharmacology. London, Churchill Livingstone, 2003, pp 244-60.
Ray A, Gupta JK, Lahiri SC. Studies on anti-inflammatory, analgesic and anti-pyretic activities of some Indian acids. Indian J Physiol Pharmacol. 1980; 24: 310-15.

Tidjani MA, Dupont C, Wepierre J. Azadirachta indica stem bark extract anti-inflammatory activity. Planta Med Phytother. 1989; 23: 259-66. 